\title{
O ENSINO DE ACÚSTICA EM CURSOS DE ENGENHARIA CIVIL EM GOIÁS E DISTRITO FEDERAL
}

\author{
Anna Julia Rodrigues Barros - rbarrosannajulia32@gmail.com \\ Gleissielle de Oliveira Costa - gleissielleoliveira@ gmail.com \\ Thalía Gabrielle Ferreira de Jesus - thaliagabrielleferreira@ gmail.com \\ Sebastião Theodoro de Moura Neto - sebas.netofsa@ gmail.com \\ Daniel Ordine Vieira Lopes - daniel.ordine@ifg.edu.br \\ Instituto Federal de Goiás - Câmpus Formosa \\ Rua 64, esq. c/ Rua 11, s/n, Expansão Parque Lago. \\ CEP: 73813-816. Formosa - GO.
}

Resumo: Este trabalho busca avaliar a incidência de temas relacionados a acústica em vários cursos de engenharia civil de instituições públicas e privadas da região de Goiás e Distrito Federal a partir de uma pesquisa documental dos Projetos Pedagógicos desses cursos. Constatamos que a atenção dada a questões de som e acústica nos documentos ainda é insuficiente dada a crescente atenção que o tema tem adquirido no desempenho de obras $e$ questões de segurança do trabalho e sustentabilidade.

Palavras-chave: Acústica. Grade curricular. Projeto Pedagógico.

\section{INTRODUÇÃO}

É crescente a preocupação com acústica, o estudo do som, na engenharia civil, tanto no projeto e desempenho final da obra quanto durante seu processo de construção. Podemos elencar como exemplos de fatores acústicos na engenharia que tem ganhado atenção: a poluição ambiental dos canteiros de obra e o incômodo gerado à população; os níveis de ruído e a saúde auditiva dos trabalhadores da construção civil; o desempenho das edificações para fins residenciais que permita privacidade e conforto acústico aos residentes; o desempenho que proporcione um bom isolamento e tratamento acústico em construções voltadas para fins específicos, como academias, salões e espaços culturais.

A cada vez maior atenção dada na engenharia civil às questões de acústica e ruído não vem somente do desejo das construtoras e dos profissionais de engenharia em proporcionar maior conforto e segurança aos usuários e trabalhadores, mas de normas e legislações específicas a estes fins. A legislação trabalhista já definia, desde 1978 com a norma regulamentadora 15 (BRASIL, 2019), os limites máximos de ruído a que um trabalhador pode ser exposto. A Associação Brasileira de Normas Técnicas define, desde a publicação da primeira edição da norma técnica NBR 10152 (1987), os limites máximos de ruído aceitáveis em diversos ambientes. Com a publicação da norma NBR 15575 (2013), critérios mais específicos de desempenho de edifícios foram definidos, incluindo desempenho acústico. Cada vez mais, as construtoras precisam estar atentas aos padrões de qualidade estabelecidos pelas normas para 
não correrem o risco de ações judiciais amparadas por exemplo pelo Código de Defesa do Consumidor, legislações trabalhistas ou outras leis regionais.

Outros autores já analisaram como empresas se adequaram a essas normas (ver por exemplo (FICHE; LAFETÁ; HORTA, 2017; KERN; SILVA; KAZMIERCZAK, 2014)). Vemos também na literatura algumas experiências de ações pontuais de se abordar acústica em cursos de graduação em engenharia (BOTARI; BOTARI, 2012; LAIER, 2004) e alguns estudos de caso de como tem sido a oferta de disciplinas relacionadas a sustentabilidade e conforto ambiental, sem especificar o conforto acústico ou poluição sonora (DORNELES; SOUZA, 2019; SANTANA, 2016). Rabbani et al. (2020) fizeram uma pesquisa documental restrita à região nordeste do Brasil de todos os cursos de Engenharia Civil e de Produção com conceito ENADE 4 ou 5, os mais altos, levantando quantos desses cursos possuem em seus currículos disciplinas que abordam sustentabilidade ou desenvolvimento sustentável. Os autores concluem apontando uma escassez desses assuntos mesmo diante da importância que possuem presentemente.

Julgamos que a preocupação com questões acústicas, durante a execução e no resultado final de uma obra, também deve estar presente na formação de um bom engenheiro e que a escassez desses assuntos nos cursos de graduação seja um problema a ser resolvido. Essa visão está em consonância com as diretrizes curriculares para os cursos de engenharia civil (BRASIL, 2019), que enfatiza na formação do engenheiro a preocupação com questões ambientais, de segurança no trabalho e de soluções inovadoras para problemas diversos e multidisciplinares. Assim, para dimensionar o problema da falta de discussão de acústica nos cursos de engenharia, pretendemos neste trabalho levantar, dentre instituições de ensino superior de uma mesma região que oferecem cursos de engenharia civil, quantas delas abordam questões de som e acústica em seus cursos de graduação, seja em disciplinas obrigatórias ou optativas, a profundidade com que o assunto é abordado.

\section{METODOLOGIA}

A pesquisa feita foi do tipo documental, e consistiu em analisar os Projetos PolíticoPedagógicos dos cursos (PPCs) e ementas de disciplinas de alguns cursos de engenharia civil de uma determinada região. Todos os documentos foram obtidos online ou, em alguns poucos casos, diretamente com membros e/ou ex-membros dessas instituições. Nos casos de documentos fornecidos ex-membros, foi feita a checagem com membros atuais para conferir se não houve mudanças posteriores nos PPCs. Para o presente estudo, a região delimitada foi o estado de Goiás e o Distrito Federal.

1) Foram identificados os cursos de engenharia civil cadastrados no CREA-GO e CREA-DF, pela lista divulgada nas webpages desses conselhos.

2) Adotou-se um critério avaliativo para as instituições que possuíam Conceito Preliminar de Curso (CPC), lista disponível no website do INEP, maior ou igual a 3. O Conceito Enade é obtido a partir de uma prova aplicada em formandos e ingressantes do curso como uma medida de avaliar o conhecimento adquirido pelos estudantes no curso. Já o CPC inclui não apenas o nível de conhecimento através da prova do ENADE, embora a considere para o cálculo, mas também infraestrutura, organização didático-pedagógica do curso e formação acadêmica dos docentes. Todas as instituições levantadas estão apresentadas no Quadro 1.

3) A partir do Quadro 1, foram coletados pelos websites dessas instituições os PPCs e ementas das disciplinas. As ementas detalhadas das instituições 16 e 17 não foram encontradas, então essas foram retiradas da análise. 
4) Foram buscadas nos PPCs e nas ementas das disciplinas as palavras-chave som, sonora, sonoro, decibel, ruído, acústica, acústico, conforto, reverberação.

5) A partir dos resultados obtidos, foram buscadas categorias de similaridade entre as diferentes instituições. A definição dessas categorias e discussão sobre elas faz parte da etapa de análise.

Quadro 1: Instituições de ensino selecionadas. Estão identificados também o turno do curso, se matutino (M), vespertino $(\mathrm{V})$, noturno $(\mathrm{N})$ ou diurno integral $(\mathrm{I})$.

\begin{tabular}{|c|c|c|c|c|c|c|c|}
\hline \# & Nome da Instituição de Ensino & Rede & Município & Turno & UF & ENADE & $\mathrm{CPC}$ \\
\hline 1 & \multirow{5}{*}{$\begin{array}{l}\text { IFG - Instituto Federal De Educação, } \\
\text { Ciência e Tecnologia De Goiás }\end{array}$} & \multirow{5}{*}{ Federal } & Goiânia & $\mathrm{N}$ & GO & 5 & 4 \\
\hline 2 & & & Jataí & $\mathrm{N}$ & GO & 4 & 4 \\
\hline 3 & & & Uruaçu & V & GO & 4 & 3 \\
\hline 4 & & & Formosa & $\mathrm{N}$ & GO & 3 & 3 \\
\hline 5 & & & $\begin{array}{l}\text { Aparecida } \\
\text { De Goiânia }\end{array}$ & $\mathrm{N}$ & GO & 4 & 3 \\
\hline 6 & $\begin{array}{l}\text { IFGoiano - Instituto Federal De Educação, } \\
\text { Ciência E Tecnologia Goiano }\end{array}$ & Federal & Rio Verde & $\mathrm{M}, \mathrm{V}$ & GO & 4 & 4 \\
\hline 7 & \multirow{3}{*}{ UEG - Universidade Estadual De Goiás } & \multirow{3}{*}{ Estadual } & Anápolis & $\mathrm{M}, \mathrm{V}$ & GO & 4 & 3 \\
\hline 8 & & & Goiânia & I & GO & 5 & 4 \\
\hline 9 & & & Catalão & $\mathrm{I}$ & GO & 4 & 3 \\
\hline 10 & UnB - Universidade De Brasília & Pública & Brasília & I & $\mathrm{DF}$ & 5 & 4 \\
\hline 11 & $\begin{array}{l}\text { Unievangélica - Centro Universitário De } \\
\text { Anápolis }\end{array}$ & Privada & Anápolis & M & GO & 3 & 3 \\
\hline 12 & Pontificia Universidade Catolica De Goiás & Privada & Goiânia & $\mathrm{M}, \mathrm{V}, \mathrm{N}$ & $\mathrm{GO}$ & 3 & 3 \\
\hline 13 & UCB - Universidade Católica De Brasília & Privada & Brasília & $\mathrm{M}$ & $\mathrm{DF}$ & 3 & 4 \\
\hline 14 & UNIP - Universidade Paulista & \begin{tabular}{|l|} 
Privada \\
\end{tabular} & Goiânia & $\mathrm{M}, \mathrm{V}, \mathrm{N}$ & GO & 2 & 3 \\
\hline 15 & $\begin{array}{l}\text { UniCEUB - Centro Universitário de } \\
\text { Brasília }\end{array}$ & Privada & Brasília & $\mathrm{M}, \mathrm{N}$ & $\mathrm{DF}$ & 3 & 3 \\
\hline 16 & $\begin{array}{l}\text { IESB - Instituto de Educação Superior de } \\
\text { Brasília }\end{array}$ & Privada & Brasília & $\mathrm{N}$ & $\mathrm{DF}$ & 4 & 4 \\
\hline 17 & $\begin{array}{l}\text { UDF - Centro de Ensino Unificado do } \\
\text { Distrito Federal }\end{array}$ & Privada & Brasília & $\mathrm{M}, \mathrm{N}$ & $\mathrm{DF}$ & 2 & 3 \\
\hline
\end{tabular}

Fonte: Dos autores. Informações coletadas nas páginas e documentos abertos de cada curso e instituição.

\section{RESULTADOS E DISCUSSÃO}

Após análise dos documentos, pôde-se notar que as instituições de ensino selecionadas podiam ser separadas em três categorias:

1) há apenas uma disciplina de física que aborda todo o assunto de física básica desde mecânica até eletromagnetismo e nenhuma disciplina específica que aborde conteúdos relacionados a som ou acústica;

2) há ao menos três períodos de física básica com uma parte dedicada a práticas de laboratório em física. Na disciplina de Física 2 o tema som pode ser inserido dentro do contexto de ondas;

3) há, além de Física 2, alguma outra disciplina que aborda questões de conforto (incluindo conforto acústico), sustentabilidade (incluindo poluição sonora) ou segurança do trabalho (incluindo questões de proteção da audição). Discorreremos brevemente sobre cada categoria. 


\subsection{Categoria 1 - Uma única disciplina de Física}

O Quadro 2 apresenta as instituições que se enquadra na categoria 1. Os cursos não continham as palavras-chave em nenhuma das ementas da grade curricular, e ao invés do ciclo de três disciplinas básicas de física continham somente uma, abordando em um único período tópicos pontuais de mecânica e eletromagnetismo.

Quadro 2: Cursos da categoria 1, com somente uma disciplina de física básica ao longo de todo o curso. $\mathrm{CH}$ significa carga horária semestral.

\begin{tabular}{|c|c|c|c|c|c|c|c|}
\hline$\#$ & IES & Municipio & UF & Disciplina & $\mathrm{CH}$ & Ementa & Palavras-chave \\
\hline 1 & UCB & Brasília & DF & Física aplicada & 80 & \multirow{2}{*}{$\begin{array}{c}\text { Tópicos diversos geralmente } \\
\text { abordados em Fisica } 1,2 \text { e } 3 \text { nos } \\
\text { outros cursos analisados }\end{array}$} & $\begin{array}{l}\text { Não, nem } \\
\text { ondulatória }\end{array}$ \\
\hline 2 & UNP & Goiânia & GO & $\begin{array}{c}\text { Complementos } \\
\text { de fisica }\end{array}$ & 60 & & Ondulatória \\
\hline
\end{tabular}

Fonte: Dos autores. Informações coletadas nas páginas e documentos abertos de cada curso e instituição.

Desde o início do século passado (ZALEWSKI; NOVAK; CARLSON, 2019) o ensino de física básica é visto como fundamental para a compreensão aprofundada dos conceitos e métodos científicos necessários nos cursos de engenharia. No Brasil, o formato de no mínimo 3 ciclos de Física Básica, abordando 1) Mecânica; 2) Aplicações de mecânica (ondas, fluidos, gravitação) e termodinâmica; 3) Eletromagnetismo é padrão nos cursos de engenharia, às vezes incluindo também uma quarta etapa, com óptica e introdução à física moderna. Autores apontam que essas disciplinas básicas contribuem para capacitar os estudantes para um bom desempenho no restante do curso e uma boa prática profissional (BUDNY; BJEDOV; LEBOLD, 1997).

Assim, encontrar cursos em que essas disciplinas são comprimidas em uma única parece ir contra à ideia de uma formação conceitual básica, aparentemente focando os esforços para o ensino de técnicas e habilidades específicas da prática da engenharia.

Sobre a possibilidade de inclusão de temas específicos de acústica dentro dessa disciplina, achamos pouco provável que em uma disciplina com tantos tópicos diferentes seja possível cobrir qualquer um deles com um pouco mais de detalhes (ver discussão sobre isso na próxima seção). Uma dessas disciplinas sequer incluía o tema ondas ou ondulatória em sua ementa, deixando nem um espaço para se trabalhar o som.

Além disso, os cursos nessa categoria não continham temas de acústica inseridos em nenhuma outra disciplina.

\subsection{Categoria 2 - Som na disciplina Física 2}

Estão dispostos no Quadro 3 os cursos das instituições levantadas que possuem 3 ou mais períodos de física, onde normalmente Física 2 contém em sua ementa conteúdos relacionados a ondas, podendo incluir o caso das ondas sonoras. Nenhuma delas possui bibliografia específica para conteúdo de acústica. Está apresentado também no Quadro 2 a carga horária de cada uma das disciplinas e se a disciplina é separada em teórico e experimental ou não. Os cursos 1, 2 e de 6 a 9 no quadro não possuem uma disciplina específica para laboratório. A prática de laboratório está inserida dentro da carga horária de uma única disciplina. Algumas dessas disciplinas especificam uma proporção de 1/3 da carga horária total correspondendo a práticas de laboratório, outras não. $O$ curso 1 possui inserido na ementa de física um detalhamento dos assuntos trabalhados em laboratório e o curso 2 possui no PPC uma descrição dos equipamentos disponíveis no laboratório, dentre eles equipamentos para se realizar experimentos de acústica. Os numerados de 3 a 5 e 10 a 13 possuem uma disciplina própria para laboratório. 
No Quadro 3 estão identificados em verde as instituições cujas ementas dos cursos contém explicitamente as palavras-chave mencionadas no item 4 da metodologia, diretamente relacionadas a som ou acústica. Em amarelo, cursos em cujas ementas de disciplinas que não conseguimos encontrar as palavras-chave, mas encontramos ondas, ondulatório(a) ou oscilações. E em laranja, ementas que não contém nem as palavras-chave principais nem relacionadas a ondas.

\begin{tabular}{|c|c|c|c|c|c|c|}
\hline$\#$ & IES & Município & $\mathrm{CH}$ & $\begin{array}{l}\text { CH - } \\
\text { Lab }\end{array}$ & Palavras-Chave & $\begin{array}{c}\text { Palavras-Chave } \\
\text { Laboratório }\end{array}$ \\
\hline 1 & UNICEUB & Brasília & 75 & - & $\begin{array}{l}\text { Oscilações, ondas } \\
\text { sonoras, som }\end{array}$ & Ondulatórios \\
\hline 2 & UNIEVANGÉLICA & Anápolis & 80 & - & $\begin{array}{c}\text { ondas, oscilações, } \\
\text { ondulatória, som }\end{array}$ & $\begin{array}{c}\text { [ondas] - somente no } \\
\text { PPC }\end{array}$ \\
\hline 3 & IFG & Goiânia & 54 & 27 & Ondas sonoras & Ondas sonoras \\
\hline 4 & UNB & Brasília & 60 & 60 & $\begin{array}{l}\text { Ondas sonoras, } \\
\text { oscilações, som }\end{array}$ & ondas sonoras, som \\
\hline 5 & UFG & Goiânia & 64 & 32 & Ondas, som & Nenhuma \\
\hline 6 & IFG & Formosa & 81 & - & $\begin{array}{c}\text { oscilatório, } \\
\text { ondulatória, ondas }\end{array}$ & - \\
\hline 7 & IFG & Aparecida de Goiânia & 81 & - & ondas, oscilações & - \\
\hline 8 & IFG & Jataí & 81 & - & Oscilações & - \\
\hline 9 & PUC & Goiânia & 90 & - & Ondas & - \\
\hline 10 & IFG & Uruaçu & 54 & 27 & Oscilações & Oscilações, Ondas \\
\hline 11 & UEG & Anápolis & 60 & 30 & Ondas, oscilações & Oscilações, ondas \\
\hline 12 & UFG & Catalão & 64 & 32 & Ondulatório & Ondulatória \\
\hline 13 & IF Goiano & Rio Verde & 60 & 40 & Ondas, oscilações & Nenhuma \\
\hline
\end{tabular}

Fonte: Dos autores. Informações coletadas nas páginas e documentos abertos de cada curso e instituição.

É interessante uma exploração um pouco maior das consequências possíveis dessas ementas. Física 2 costuma ser uma disciplina em que o livro faz a ementa. Normalmente escolhe-se um livro-texto tradicionalmente utilizado, como dos autores Halliday, Resnick e Walker (2016), Tipler e Mosca (2009), Sears, Zemansky, Freedman e Young (2008) ou outras edições desses livros ou ainda de outros autores que seguem o mesmo formato e similar sequência de conteúdos e segue-se dele, capítulo por capítulo. Os conteúdos abordados nesses livros, e consequentemente nas disciplinas de Física 2, são

- Equilíbrio de Corpo Extenso e Elasticidade

- Gravitação

- Fluidos (hidrodinâmica e hidrostática)

- Oscilações (movimento harmônico, oscilações simples, amortecidas e forçadas)

- Ondas e Som (perturbação e onda, fenômenos ondulatórios, sobreposição de ondas, intensidade e energia de ondas) 
- Termodinâmica (calor, temperatura, teoria cinética dos gases e leis da termodinâmica)

Ilustramos na Figura 1 a atenção dada a cada assunto nos três livros mencionados bastante utilizados, por uma análise do número de páginas do livro referentes àquele assunto. Excluímos da contagem as páginas de exercícios. Agrupamos todos os capítulos referentes a ondas e som em uma única categoria Ondas e Som pois cada livro organiza os assuntos ondas e som de maneira diferente, ou dedicando seções e capítulos específicos para som ou mesclando com discussões de ondas em geral.

Figura 1: Proporção do número de páginas para cada tema nos livros frequentemente usados de Física 2.

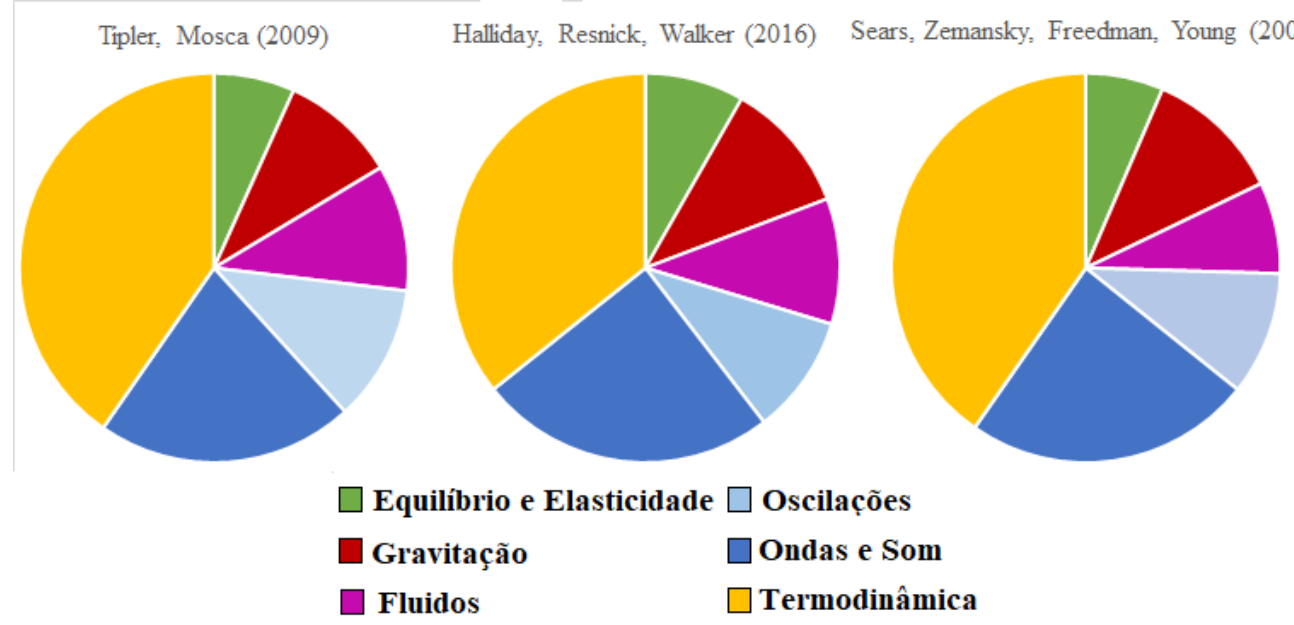

Fonte: dos autores

Todo o conteúdo presente nas ementas e nos livros adotados é bastante extenso para uma disciplina de aproximadamente 90 horas (sendo práticas de laboratório 1/3 do total), com conteúdos que não se relacionam tão bem conceitualmente quanto na Física 1 (movimento, forças e energia) ou na Física 3 (eletromagnetismo). Cada tópico é quase independente dos demais, envolvendo conceitos novos. Algumas poucas instituições oferecem horários complementares, com monitores bolsistas dedicados a atividades de resoluções de exercícios e esclarecimento de dúvidas. Mas boa parte não dispõe disso ou quando dispõe é pouco aproveitado quando os estudantes são também trabalhadores (principalmente nos cursos noturnos). Assim, todo o conteúdo da disciplina, com a parte conceitual, exemplos de exercícios e esclarecimento de dúvidas fica muitas vezes restrito às 54 horas (ou 60 horas) usualmente em sala de aula.

Como muitas vezes não é possível cobrir todo o conteúdo de maneira aprofundada, a menos que haja uma política pedagógica bem específica do curso fica a critério do professor quais conteúdos priorizar. Em cursos de engenharia normalmente são físicos que lecionam a disciplina Física 2, sem necessariamente alguma experiência com a prática profissional em engenharia, o que torna essa escolha ainda mais complicada. O tema equilíbrio e elasticidade não pode ser negligenciado, pois é talvez o conceito básico mais importante da engenharia civil, isto é, conseguir o equilíbrio de forças para garantir a estabilidade dos edifícios. O estudo de fluidos é fundamental para entender instalações hidráulicas e escoamento, que serão trabalhadas em detalhes e em situações específicas em disciplinas mais avançadas. A parte de propriedades térmicas dos materiais, dentro do grupo identificado na Figura 1 como termodinâmica, também é bastante relevante para a engenharia, dada a importância por exemplo das juntas de dilatação em estruturas, sendo os demais assuntos como teoria cinética dos gases e leis da termodinâmica muitas vezes reduzidos em importância. 
O estudo de som e acústica, no contexto da disciplina Física 2, é mesclado ao estudo de ondas de maneira geral. O estudo de ondas por sua vez é mais compreensível após o estudo de movimento oscilatório, uma vez que uma onda pode ser entendida como uma coleção de osciladores. Assim se fazem necessárias várias aulas para se possa chegar aos assuntos específicos de som, fenômenos sonoros, energia e intensidade sonora com os conceitos prévios adequados para uma compreensão um pouco mais aprofundada dos temas. É comum que muitas ementas sequer especifiquem o termo som (ou derivados) no conteúdo a ser trabalhado (como os cursos 3, 4, 5, 6, 10, 11 e 12 do Quadro 3), de forma que o professor se assim desejar pode simplesmente deixar de fora o fenômeno ondulatório sonoro e abordar somente conhecimentos sobre ondas de maneira geral.

Se reconhecermos a importância do conhecimento sobre som e acústica para o futuro engenheiro, defendemos que é necessário que ao menos seja explicitamente destacado na ementa da disciplina de física onde se aborda ondas que se fale no mínimo sobre som e intensidade sonora, para que esse caso particular de onda não seja negligenciado.

Seria interessante, como um trabalho futuro, um levantamento com estudantes de engenharia de diferentes instituições para avaliar o que dos assuntos de som e acústica eles aprenderam na disciplina de Física 2, ou um levantamento com diversos professores da disciplina sobre a atenção que normalmente dão ao tema.

\subsection{Categoria 3 - Disciplinas específicas}

Quatro instituições do levantamento apresentavam assuntos relacionados a som e acústica em alguma outra disciplina além de Física 2. Discorreremos brevemente sobre elas, organizando por instituição.

- UnB (Brasília - DF)

Controle de poluição - $\mathrm{CH}$ : 60h: Trata de política ambiental e poluição de maneira geral (causas, consequências, controle, formas de medição, etc.) abordando poluição da água, do ar, do solo, sonora, estética e por radiação.

Saneamento Ambiental - CH: 60h: Também trata de controle de poluição, dando maior ênfase a poluição da água e tratamento de resíduos. Não contém em sua ementa menção especial a poluição sonora, embora mencione em seu conteúdo programático.

- UEG (Anápolis - GO)

Aeroportos, Portos e Vias Navegáveis - $\mathrm{CH}$ : 60h: Aborda a construção, características e funcionamento dessas estruturas. Inclui em sua ementa ruído aeroportuário.

- IFGoiano (Rio Verde - GO)

Higiene e Segurança do Trabalho: Trata de legislação sobre segurança, Local de trabalho, Insalubridade e riscos no trabalho. Inclui riscos provocados por ruídos sonoros.

Edifícios Sustentáveis, Clima e Conforto Humano: Aborda sustentabilidade ambiental, conforto térmico, luminoso e acústico e avaliação pós-ocupação dos edifícios.

Vemos nesta categoria os temas de conforto acústico, poluição sonora ou ruído inseridos em outras disciplinas. Consideramos isso positivo, pois permite visualizar esses temas dentro de um contexto maior (poluição, segurança ou conforto), e aplicado a temas específicos da engenharia. Algumas dessas disciplinas, por exemplo, detalham as técnicas de medição das grandezas que definem os parâmetros de conforto ou de poluição, mostrando que há uma técnica estabelecida para essas medições. Em nenhuma das ementas dessas disciplinas foi encontrada bibliografia específica para os temas de acústica nem normas de desempenho, medição ou limites relacionados a acústica, mas a presença nas ementas já garante uma atenção para esses temas. 


\section{CONSIDERAÇÕES FINAIS}

Das instituições de ensino de nosso levantamento constatamos que a maioria delas (76\%) não trata suficientemente de questões sonoras aplicadas à engenharia, seja visando segurança do trabalho devido a intensos ruídos, visando preocupação com poluição ambiental em canteiros de obras ou visando um bom desempenho acústico nas obras para o conforto das pessoas que a utilizarem. Destacamos que mesmo em seu nível mais básico, nas disciplinas de Física 2 onde o tema ondas é abordado, aí incluindo ondas sonoras e suas propriedades, é possível que se dê pouca ou nenhuma atenção ao tema específico do som. Para evitar isso recomendamos que ao menos nas disciplinas de Física 2 as instituições incluam em suas ementas os termos som, acústica ou intensidade sonora.

Ao mesmo tempo, foi constatado que em alguns cursos temas de conforto acústico, poluição sonora, ruídos provocados por máquinas ou veículos estão inseridos em disciplinas não específicas de acústica. A inclusão desses temas em diversas disciplinas diferentes, mesmo que de maneira não muito aprofundada, pode ser um primeiro passo para despertar a preocupação e atenção necessária com questões de acústica na formação da nova geração de engenheiros. Esperamos que essa preocupação nos cursos de engenharia seja crescente, refletindo numa maior preocupação com questões acústicas na prática desses profissionais.

\section{Agradecimentos}

Os autores agradecem ao professor Cléber Alves da Costa pela grande ajuda disponibilizada ao longo das etapas deste e de outros trabalhos.

\section{REFERÊNCIAS}

ASSOCIAÇÃO BRASILEIRA DE NORMAS TÉCNICAS. NBR 10152: Níveis de ruído para conforto acústico: procedimento. Rio de Janeiro, 1987.

. NBR 15575: Edificações Habitacionais - Desempenho. Rio de Janeiro, 2013.

BOTARI, Alexandre; BOTARI, Janaina Conversani. Diagnóstico e Análise Intervencional da Aprendizagem Significativa de Física Acústica no Ensino da Construção Civil. In: SAFETY, HEALTH AND ENVIRONMENT WORLD CONGRESS, 12. 2012, São Paulo. Anais. São Paulo: SHEWC, 2012. p. 571-576.

BRASIL. Ministério da Saúde. NR 15: Atividades e Operações Insalubres. Brasília: Gabinete do Ministro, 2019.

BRASIL. Ministério da Educação. Conselho Nacional de Educação. Diretrizes Curriculares Nacionais do Curso de Graduação em Engenharia (DCNs de Engenharia). Gabinete do Ministro, 2019.

BUDNY, Dan; BJEDOV, Goranka; LEBOLD, William. Assessment of the impact of the freshman engineering courses. Journal of Engineering Education, [S. l.], v. 2, n. May, p. 1100-1106, 1997. DOI: 10.1109/fie.1997.636047.

DORNELES, Viviane Rodrigues; DE SOUZA, Marco Antônio Simões. Abordagem ambiental nos currículos dos cursos de engenharia de uma universidade do Sul do Brasil. 
Natural Resources, [S. l.], v. 9, n. 2, p. 43-58, 2019.

FICHE, Lorena; LAFETÁ, Bruna; HORTA, Frederico. Avaliação das mudanças das diretrizes acústicas após a revisão da NBR 15575 (2013) em Belo Horizonte. Revista Petra, Belo Horizonte, v. 3, n. 2, p. 163-178, 2017.

HALLIDAY, David; RESNICK, Robert; WALKER, Jearl. Fundamentos de Física vol. 2. Rio de Janeiro: LTC-Livros Técnicos e Cientıficos Editora SA, 2016.

KERN, Andrea Parisi; SILVA, Adriana; KAZMIERCZAK, Claudio de Souza Kazmierczak Souza. O Processo De Implantação De Normas De Desempenho Na Construção: Um Comparativo Entre a Espanha (Cte) E Brasil (Nbr 15575/2013). Gestão \& Tecnologia de Projetos, São Paulo, v. 9, n. 1, p. 89-101, jan./jun. 2014.

LAIER, José Elias. Estudo da disciplina de acústica ambiental para engenheiros. In: XXXII Congresso Brasileiro de Ensino de Engenharia 2004, Anais. Brasília, DF, 2004.

RABBANI, Emilia Rahnemay Kohlman; SILVA, Alyx Diêgo Oliveira; MOCOCK, Juliana Ferreira Bezerra; MELO, Felipe Guilherme de Oliveira. O ensino dos conceitos da sustentabilidade nos melhores cursos de Engenharia Civil e de Produção na região Nordeste. In: Série Educar - Volume 33 - Ensino Superior. Belo Horizonte: Poisson, 2020. p. 35-43.

SANTANA, Leonardo Nunes. A sustentabilidade nas instituições de ensino superior: Visões e práticas de sustentabilidade ambiental nos cursos de engenharia civil em duas universidades do estado de Sergipe. Tese (Doutorado em Educação) - Faculdade de Educação, Pontifícia Universidade Católica do Rio Grande do Sul - PUCRS. Porto Alegre. p. $167,2016$.

SEARS, Francis Weston; ZEMANSKY, Mark Waldo; FEEDMAN, R. A.; YOUNG, H. D. Física 2. 12a. ed. São Paulo: Pearson Addison Wesley, 2008.

TIPLER, Paul A.; MOSCA, Gene. Física Para Cientistas e Engenheiros. Rio de Janeiro: LTC-Livros Técnicos e Cientıficos Editora SA, 2009.

ZALEWSKI, Janusz; NOVAK, Gregor; CARLSON, Randall E. An overview of teaching physics for undergraduates in engineering environments. Education Sciences, [S. l.], v. 9, n. 4, 2019. 


\title{
ACOUSTICS EDUCATION IN CIVIL ENGINEERING COURSES IN GOIÁS AND THE FEDERAL DISTRICT
}

\begin{abstract}
The present work aims to assess the incidence of acoustics related themes in a number of civil engineering courses of public and private institutions in the region of Goias and the Federal District via a documentary research through course syllabus of these courses. We observe that the attention given to questions of sound and acoustics in the documents is still insufficient considering the growing attention the theme has received in building performance and issues related to work safety and sustainability.
\end{abstract}

Keywords: Acoustics. Course Curriculum. Syllabus. 